\title{
Nonlinear Mixing Model of Mixed Pixels in Remote Sensing Satellite Images Taking Into Account Landscape
}

\author{
Verification of the proposed nonlinear pixed pixel model through simulation studies
}

\author{
Kohei Arai ${ }^{1}$ \\ Graduate School of Science and Engineering \\ Saga University \\ Saga City, Japan
}

\begin{abstract}
Nonlinear mixing model of mixed pixels in remote sensing satellite images taking into account landscape is proposed. Most of linear mixing models of mixed pixels do not work so well because the mixed pixels consist of several ground cover targets in a nonlinear basis essentially. In particular, mixing model should be nonlinear because reflected photons from a ground cover target are scattered with atmospheric continuants and then reflected by the other or same ground cover targets. Therefore, mixing model has to be nonlinear. Monte Carlo Ray Tracing based nonlinear mixing model is proposed and simulated. Simulation results show a validity of the proposed nonlinear mixed pixel model.
\end{abstract}

Keywords - nonlinearity; mixed pixels; Monte Carlo Ray Tracing; landscape

\section{INTRODUCTION}

Most of linear mixing models of mixed pixels do not work so well because the mixed pixels consist of several ground cover targets in a nonlinear basis essentially. In particular, mixing model should be nonlinear because reflected photons from a ground cover target are scattered among the ground cover targets and with the atmospheric continuants and then reflected by the other or same ground cover targets. Therefore, mixing model has to be nonlinear essentially. Also nonlinear mixing model has to take into account landscape.

The pixels in earth observed images which are acquired with Visible to Near Infrared: VNIR sensors onboard remote sensing satellites are, essentially mixed pixels (mixels) which consists of several ground cover materials [1]. Some mixel model is required for analysis such as un-mixing of the mixel in concern [2],[3]. Typical mixel is linear mixing model which is represented by linear combination of several ground cover materials with mixing ratio for each material [4]. It is not always true that the linear mixel model is appropriate [5]. Due to the influences from multiple reflections between the atmosphere and ground, multiple scattering in the atmosphere on the observed radiance from the ground surface, pixel mixture model is essentially non-linear rather than linear. These influence is interpreted as adjacency effect [6].[7].
Landscape based nonlinear mixing model of the mixed pixels of remote sensing satellite images which takes into account scattering due to the atmospheric molecules and aerosol particles in the atmosphere is proposed. The proposed model is based on the well-known Monte Carlo Ray Tracing: MCRT model [8]. Simulation cell which is composed with the atmosphere, extrat errestrial solar irradiance and ground surface is assumed. Landscape is modeled with the ground surface cells by referencing to Digital Elevation Model: DEM which is derived from stereo pair of visible to near infrared radiometers onboard remote sensing satellites.

In the atmosphere, there are Rayleigh and Mie scatterings due to the atmospheric molecules and aerosol particles, respectively. Therefore, refractive index and size distribution has to be determined or designated for aerosol particles. The proposed nonlinear mixing model is primarily for analyzing mixed pixels: Mixels which are acquired with visible to near infrared radiometer. Therefore, water vapor, ozone (and of course, oxygen and nitrogen gasses) is assumed to be the atmospheric continuants because these atmospheric continuants have absorption in the wavelength region. The proposed model is realized in a computer simulation and is validated.

The following section describes the proposed nonlinear mixing model followed by a method for computer simulation method. Then the proposed nonlinear model is validated with MCRT model based computer simulation. Finally, conclusion is described together with some discussions.

\section{Proposed NonlineAr MiXING MOdEL OF MiXED PIXELS IN REMOTE SENSING SATELLITE IMAGES}

\section{A. Monte Carlo Ray Tracing Simulation Model}

Figure 1 shows simulation cell of MCRT model for the proposed nonlinear mixing model of Mixels of visible to near infrared radiometer acquired remote sensing satellite images. The simulation cell size is $50 \mathrm{~km}$ by $50 \mathrm{~km}$ by $50 \mathrm{~km}$. The ground surface parameters are reflectance and elevation while those of the atmosphere are optical depth of the atmospheric molecules and aerosol particles. 


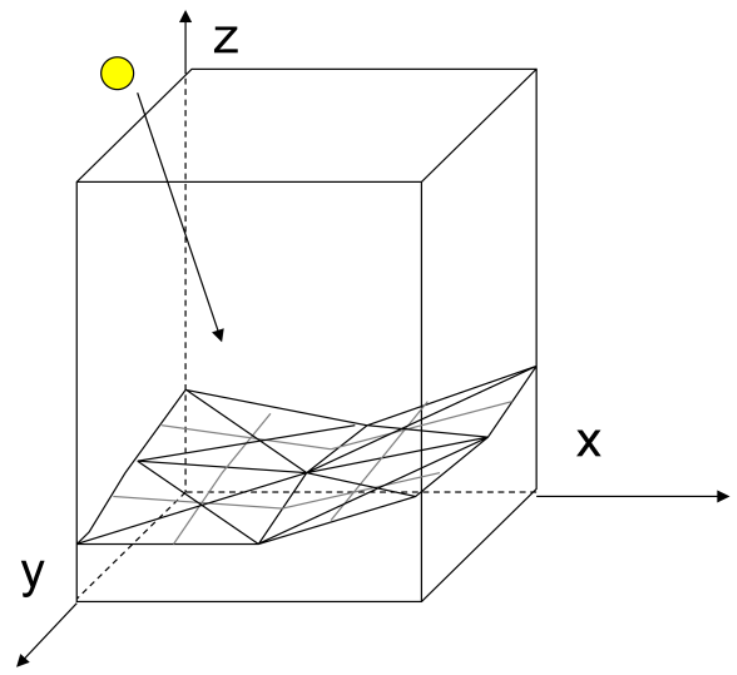

Figure 1. Simulation cell for Monte Carlo Ray Tracing

MCRT process flow is shown in Figure 2. Photon from the sun is input from the top of the atmosphere (the top of the simulation cell). Travel length of the photon is calculated with optical depth of the atmospheric molecule and that of aerosol. There are two components in the atmosphere; molecule and aerosol particles while three are also two components, water and particles; suspended solid and phytoplankton in the ocean. When the photon meets molecule or aerosol (the meeting probability with molecule and aerosol depends on their optical depth), then the photon scattered in accordance with scattering properties of molecule and aerosol. The scattering property is called as phase function.

In the visible to near infrared wavelength region, the scattering by molecule is followed by Rayleigh scattering law [1] while that by aerosol is followed by Mie scattering law [1]. On the other hands, the photons which reach on the ground are reflected and absorbed at the surface depending on the surface reflectance.

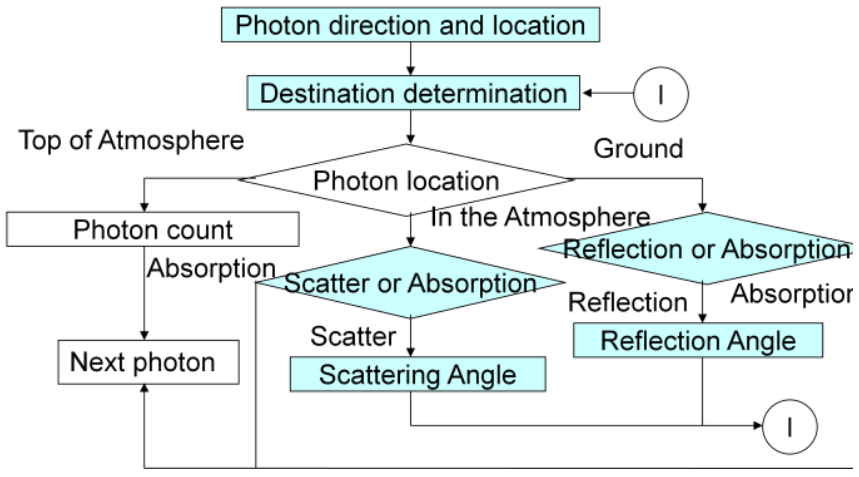

Figure 2. MCRT process flow.

\section{B. Ground Surface Model}

Ground cover targets are situated with their own reflectance and slopes. One pixel, Instantaneous Field of View: IFOV can be divided into four by four sub-pixels as shown in Figure 3.
Simulation cell size is $50 \mathrm{~km}$ cube. Therefore, one subpixel is composed with $1 \mathrm{~km}$ by $1 \mathrm{~km}$ (50 by 50 sub-pixels in the simulation cell). Also the numbers in the sub-pixel, Ref[a][b] denotes the reflectance of the ground surface. Elevation at the four corners of a pixel can be derived from DEM which is obtained with stereo pair of visible to near infrared radiometer imagery data. Elevation at the center of the pixel in concern can be estimated with the elevation data at the neighboring four corners as shown in Figure 4. Thus the slopes of the triangles which are shown in Figure 4 are determined.

Three points of the triangle are known. Therefore, equations for representation of triangles are known as shown in Figure 5. Also one pixel is composed with four by four subpixels and consists of 16 of sub-surface slopes as shown in Figure 6. Elevations of the four corners of the sub-pixel are given by DEM which is derived from stereo pair of images of visible to near infrared radiometer onboard remote sensing satellites. Therefore, slopes are calculated for all the 16 of subsurface of pixel.

\begin{tabular}{|l|l|l|l|}
\hline $\operatorname{Ref[0][0]}$ & $\operatorname{Ref[0][1]}$ & $\operatorname{Ref[0][2]}$ & $\operatorname{Ref[0][3]}$ \\
\hline $\operatorname{Ref[1][0]}$ & $\operatorname{Ref[1][1]}$ & $\operatorname{Ref[1][2]}$ & $\operatorname{Ref[1][3]}$ \\
\hline $\operatorname{Ref[2][0]}$ & $\operatorname{Ref[2][1]}$ & $\operatorname{Ref[2][2]}$ & $\operatorname{Ref[2][3]}$ \\
\hline $\operatorname{Ref[3][0]}$ & $\operatorname{Ref[3][1]}$ & $\operatorname{Ref[3][2]}$ & $\operatorname{Ref[3][3]}$ \\
\hline
\end{tabular}

Figure 3. Visible to near infrared radiometer acquired pixel is assumed to be combined four by four sub-pixels.

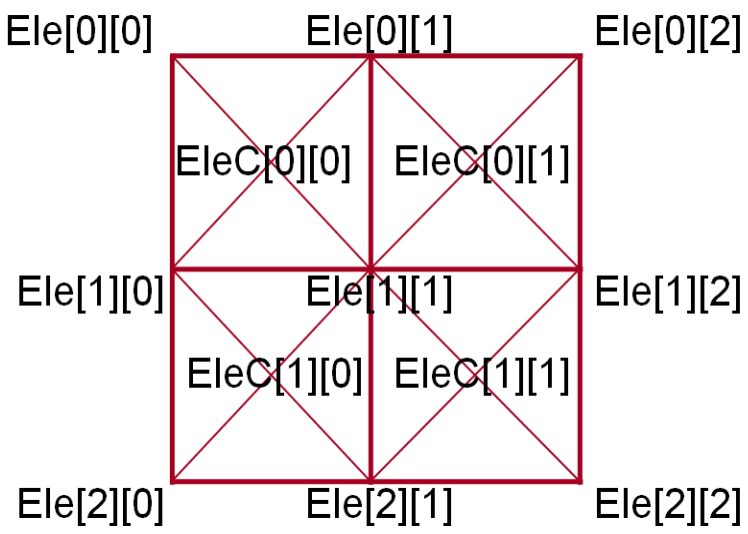

Figure 4. Landscape model of the pixel in concern. 


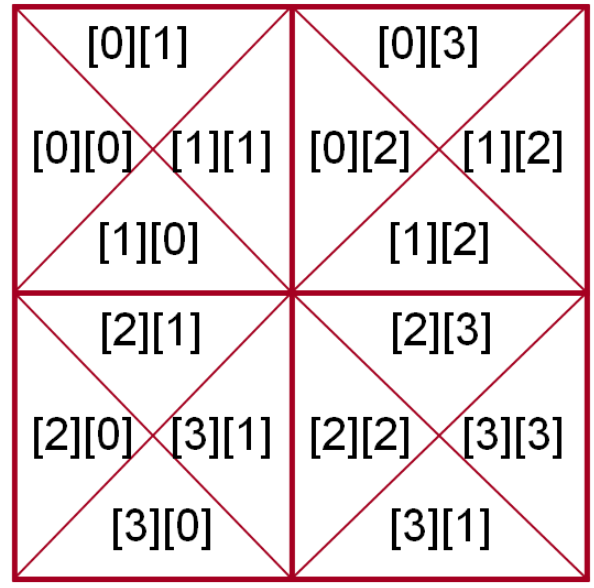

Figure 5. Calculation of triangle equation of the pixel in concern

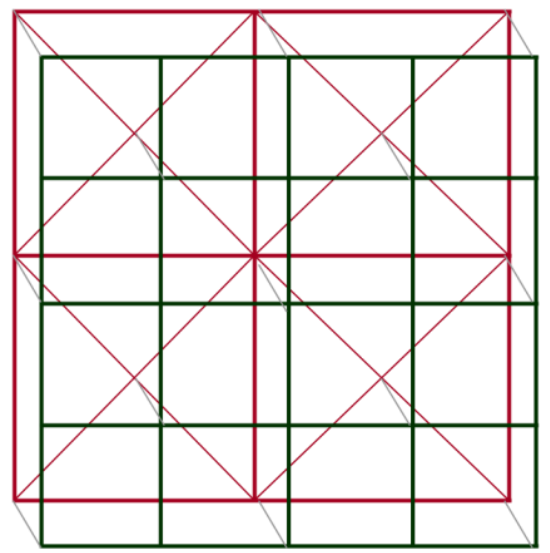

Figure 6. Pixel which is composed with four by four sub-pixels and consists of 16 of sub-surface slopes.

\section{EXPERIMENTS}

\section{A. Preliminary Simulation Study}

Figure 7 shows ground surface model. Algorithm for determination of elevation is as follows,

- $\mathrm{A}+\mathrm{B}=20, \mathrm{~A}>\mathrm{B}$

- Average elevation $=10$

- $\mathrm{A}=10,11, \ldots, 19,20$

- $\quad \mathrm{B}=10,9, \ldots, 1,0$

- $\quad$ Standard deviation $=(\mathrm{A}-10) \times \sqrt{ } 2$

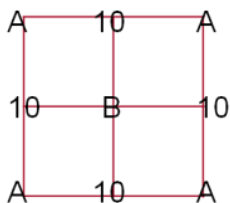

Figure 7. GROUND surface model used for simulation study

Thus the mean elevation of the surface in the simulation cell is 10 and standard deviation of elevation square root 2 (0.5). 8 ,

There are four types of photon passes as shown in Figure
(1) Photons are scattered by atmospheric molecules and aerosol particles and are come out from the top of the atmosphere,

(2) Photons are scattered by atmospheric molecules and aerosol particles and are absorbed in the atmosphere,

(3) Photons are scattered by atmospheric molecules and aerosol particles and are reached on the ground the photons are come out from the top of the atmosphere,

(4) Photons are scattered by atmospheric molecules and aerosol particles and are absorbed on the ground.

In the simulation, optical depth of the atmospheric molecules is set at 0.14 while that of the aerosol particles is set at 0.35 . Meanwhile, surface reflectance is set at $0.1,0.15$, and 0.2 . The percentage ratio of photon pass types is shown in Table 1. The percentage ratios of photon pass types of (1) and (2) are not related to surface reflectance. On the other hands, the percentage ratios of photon pass types of (3) and (4) are depending upon the surface reflectance obviously. Therefore, average ratio of the photons which reaches on the ground depends on surface reflectance as the result.

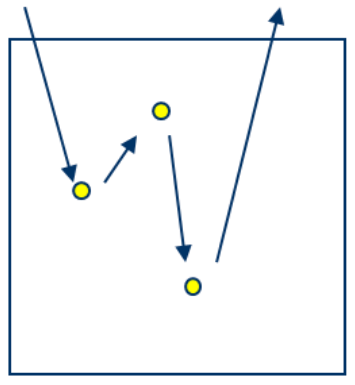

(1)

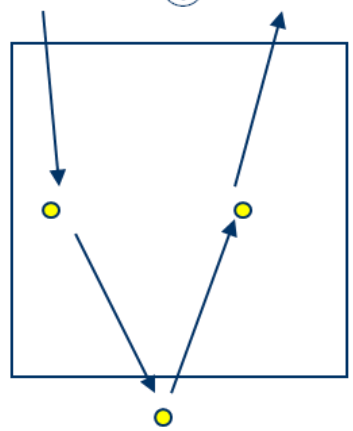

(3)

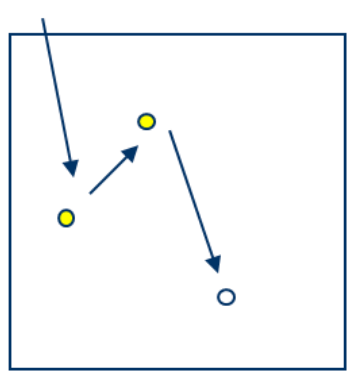

(2)

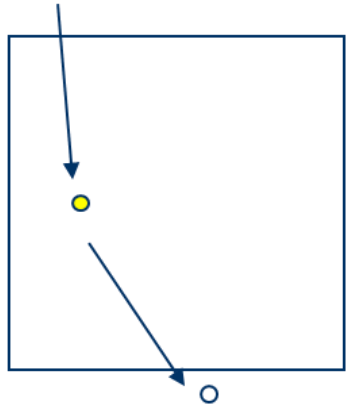

(4)
Figure 8. Four types of photons' behavior

It is obvious that the Top of the Atmosphere: TOA radiance and average ratio of the photons which reaches on the ground depends on surface reflectance and surface elevation differences. Table 1 shows preliminary simulation results. The contribution factors to the TOA radiance are shown in Table 1 as function of surface reflectance. The most dominant factor is No.4 followed by No.1.

The contributions of No.2 and No.3 are almost same and are smaller than those for No.1 and No.4. 
TABLE 1. TABLE I. PRELIMINARY SimUlation Results REFLECTANCE

\begin{tabular}{|l|l|l|l|}
\cline { 2 - 4 } \multicolumn{1}{c|}{} & \multicolumn{2}{l}{ Reflectance } \\
\cline { 2 - 4 } \multicolumn{1}{c|}{} & 0.1 & 0.15 & 0.2 \\
\hline (1) & $19.30 \%$ & $19.30 \%$ & $19.30 \%$ \\
\hline (2) & $8.20 \%$ & $8.20 \%$ & $8.20 \%$ \\
\hline (3) & $5.40 \%$ & $8.22 \%$ & $11.10 \%$ \\
\hline (4) & $67.1 \%$ & $64.28 \%$ & $61.40 \%$ \\
\hline ave_hit_grd & 0.739 & 0.745 & 0.753 \\
\hline TOArad & 0.0401 & 0.0447 & 0.0494 \\
\hline
\end{tabular}

Figure 9 (a) shows the TOA radiance as a function of elevation difference while Figure 9 (b) shows the average ratio of the photons which reaches on the ground. Furthermore, Figure 9 (c) shows the percentage ratio of the photons which reaches on the ground. As the results, the percentage ratio of the photons which are reflected on the ground depends on the elevation difference, surface roughness.

(a)TOA radiance

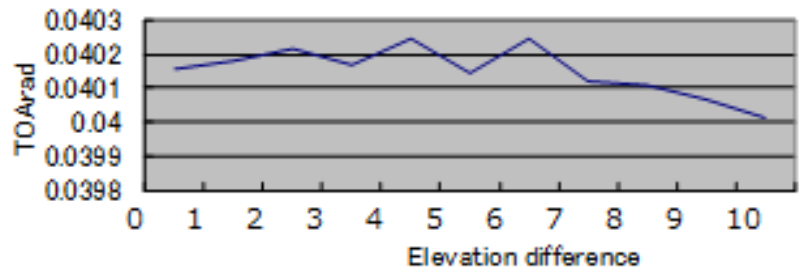

(b)Average ratio of the photons which reaches on the ground

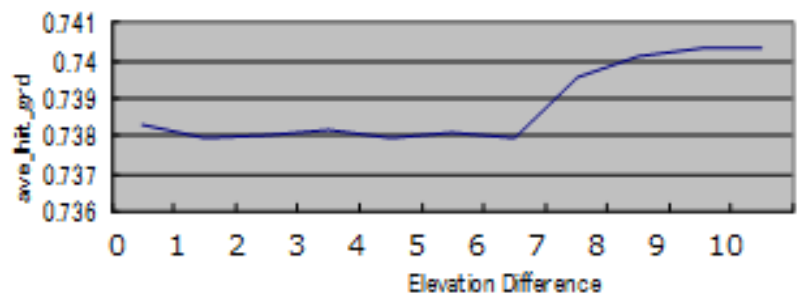

(c)Percentage ratio of the photons which reaches on the ground

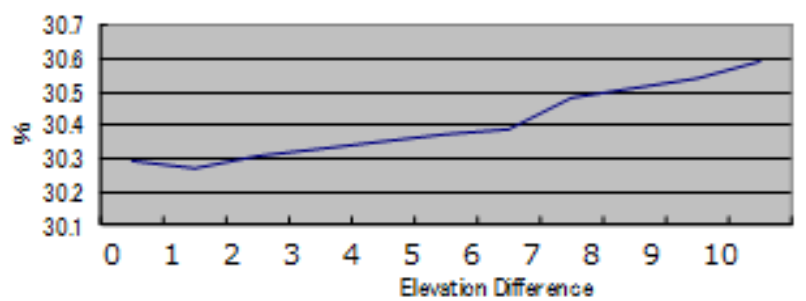

Figure 9. TOA radiance and percentage ratio of the photons which reaches on the ground as a function of elevation differences ranges from 0 to 10
Even if the average elevation is same, TOA radiance decreases in accordance with elevation difference due to the fact that photons are reflected several times so that TOA radiance decreases in accordance increasing of surface roughness. Simulation results of the number of photons which are reflected in the atmosphere and on the ground are shown in Table 2.

TABLE 2. Table II. Simulation Results Of The Number Of Photons WHICH ARE REFLECTED IN THE ATMOSPHERE AND ON THE GROUND

\begin{tabular}{|l|l|l|l|}
\cline { 2 - 3 } \multicolumn{1}{c|}{} & \multicolumn{2}{|l|}{ Atmosphere } & \multirow{2}{*}{ Surface } \\
\cline { 2 - 3 } \multicolumn{1}{c|}{} & Molecule & Aerosol & \\
\hline Reflectance & 1 & 0.9318 & $0.1 \sim 0.2$ \\
\hline Maximum No. of reflected photons & 24 & 4 \\
\hline Average No. of reflected photons & 1.9 & 0.75 \\
\hline
\end{tabular}

There are absorption and scattering due to aerosol particles. Therefore, reflectance of aerosol is not 1.0. $6.72 \%$ of photons are absorbed by aerosol particles.

Even though the surface reflectance on the ground is 0.1 to $0.2,75 \%$ of photons are reflected on the ground surface in average.

\section{B. Simulation Study with a Variety of Parameters}

The following 6 parameters are taken into account in the simulation study,

Standard deviation of surface elevation: $S=0.25-1.0,(0.5)$

Surface reflectance: ref $=0.3-0.7,(0.3)$

Optical depth of the atmospheric molecule: tau_ray $=0.1$ $0.35,(0.35)$

Aerosol optical depth: tau_aero=0.1-0.5, (0.14)

Mean of elevation: ave_Ele=0-20, (10)

Surface slope: 0-30 degree, (0 degree)

where the number in the bracket denotes default values. In the simulation study, average number of photons which hit on the ground, TOA radiance, and average number of photons which reflected on the ground and scattered in the atmosphere then reflected on the ground again are major concerns. Furthermore, pass-radiance, sky-light, reflected radiance on the ground, absorbed radiance in the ground is also concern. Ratio against average of concerned parameters is calculated. The simulation results are shown in Figure 10.

The parameters are r, (1) average number of photons which hit on the ground, (2) TOA radiance, (3) average number of photons which reflected on the ground and scattered in the atmosphere then reflected on the ground again, (4) pass-radiance, (5) sky-light, (6) reflected radiance on the ground, (7) absorbed radiance in the ground. 


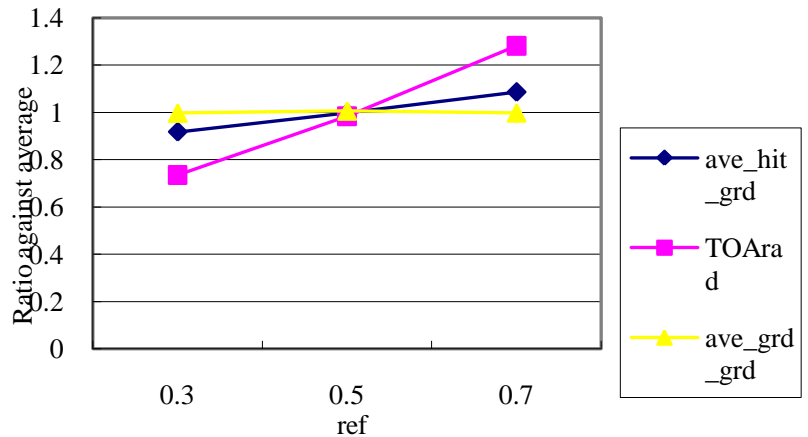

(a)Reflectance

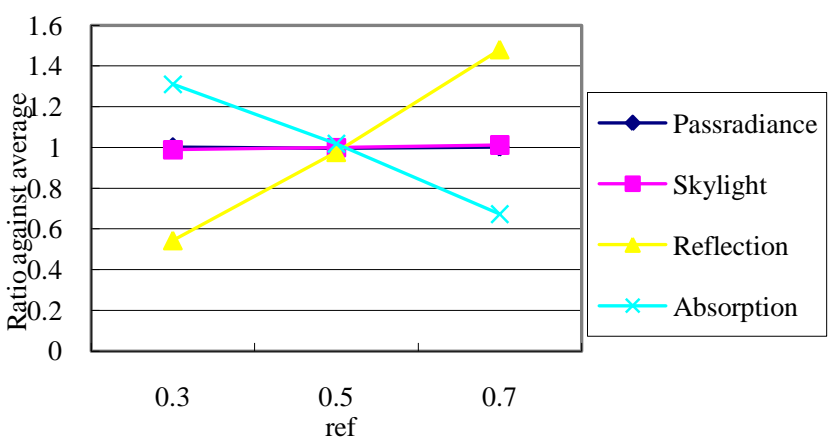

(b)Reflectance

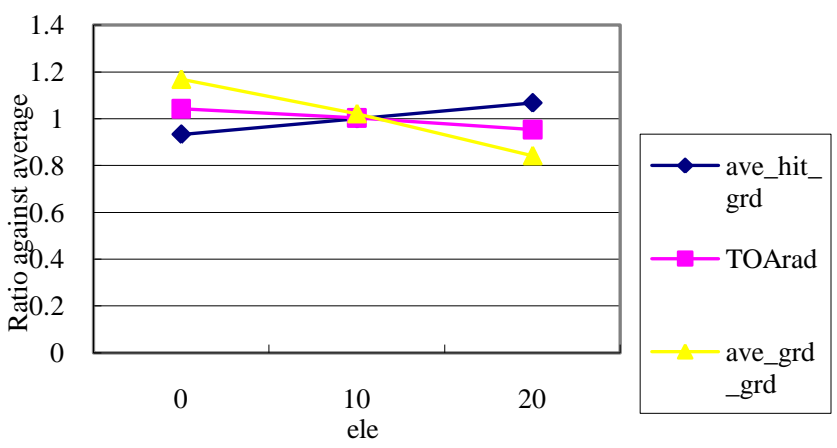

(c)Elevation

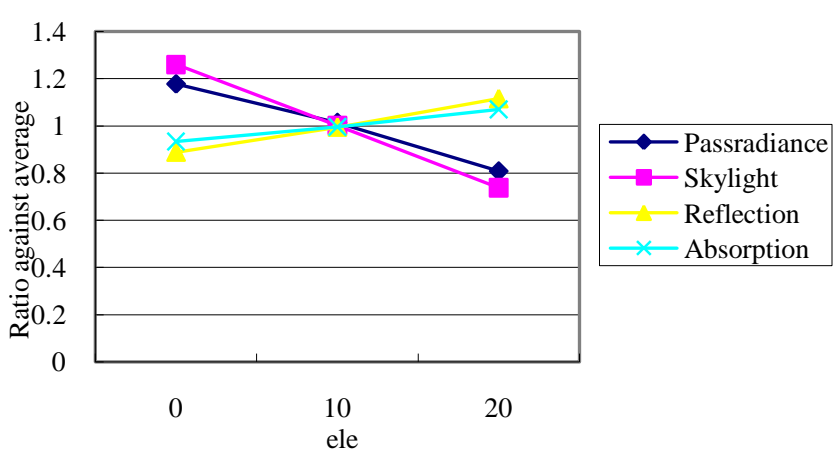

(d)Elevation

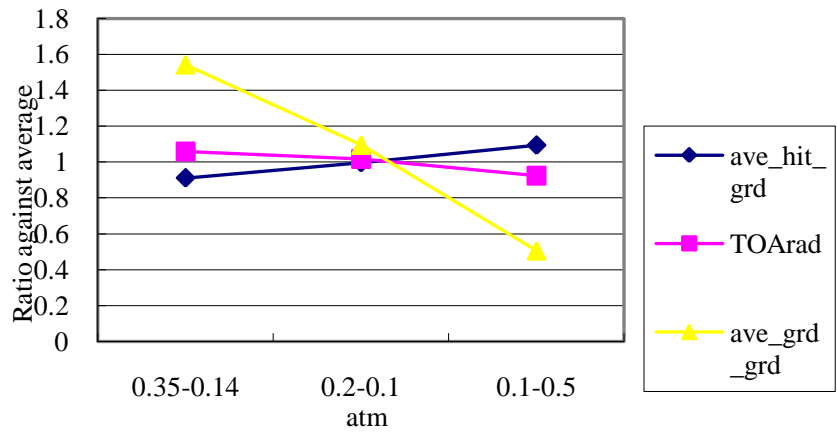

(e)Optical depth

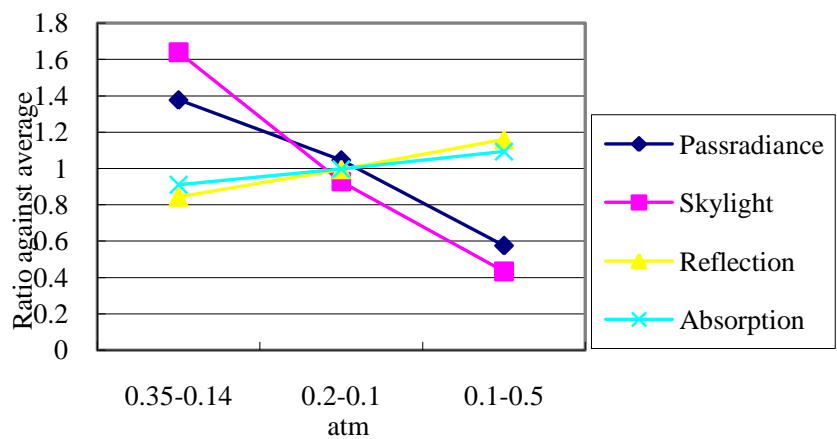

(f)Optical depth

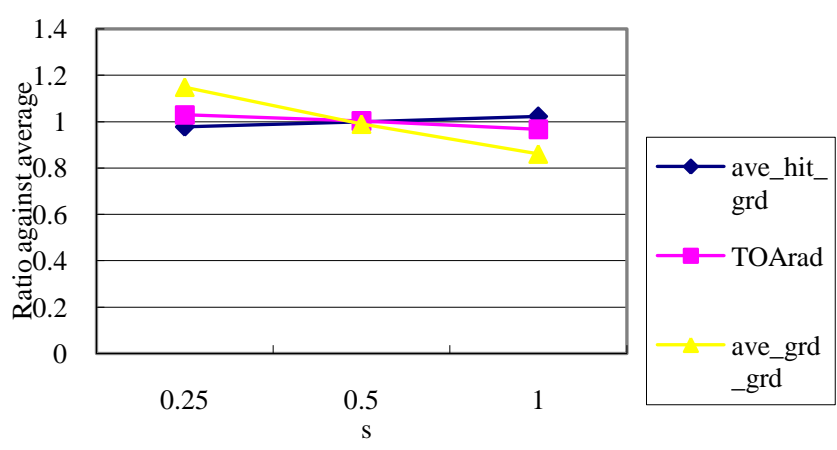

(g)Standard deviation

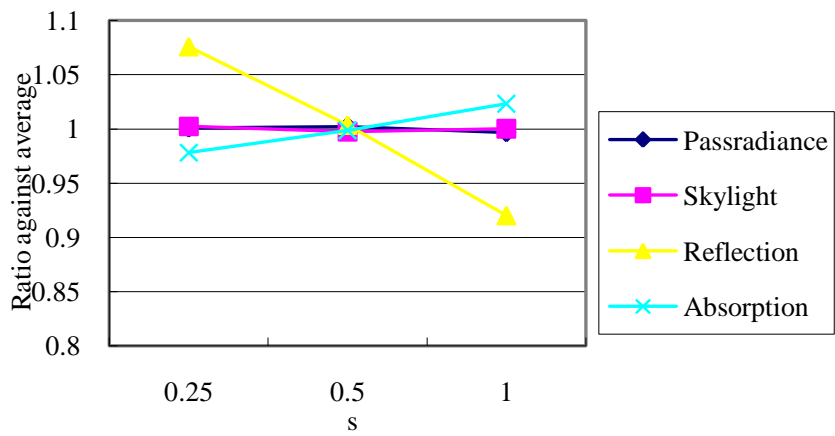

(h)Standard deviation

Figure 10. Ratio against average of concerned parameter 
Meanwhile, surface slope effect is evaluated with two adjacent slopes ( 0 versus 0,15 versus 0,30 versus 0,15 versus 15,30 versus 15 and 30 versus 30 in unit of degree). Table 3 and 4 shows the results.

TABLE 3. Slope EFFect On Average Number OF PHotons Which Hit On The Ground, Toa Radiance, AND AVERAGe Number OF PHOTONS WHICH REFLECTED ON THE GROUND AND SCATTERED IN THE ATMOSPHERE THEN REFLECTED ON THE GROUND AGAIN

\begin{tabular}{|l|l|l|l|l|l|l|}
\hline & $0-0$ & $15-0$ & $30-0$ & $15-15$ & $30-15$ & $30-30$ \\
\hline $\begin{array}{l}\text { ave_hi } \\
\text { t_grd }\end{array}$ & 0.8109 & 0.8114 & 0.8253 & 0.8111 & 0.8204 & 0.8212 \\
\hline $\begin{array}{l}\text { TOAr } \\
\text { ad }\end{array}$ & 0.0548 & 0.0547 & 0.0534 & 0.0546 & 0.0540 & 0.0537 \\
\hline $\begin{array}{l}\text { ave_g } \\
\text { rd_grd }\end{array}$ & 1.9744 & 1.9618 & 1.8656 & 1.9605 & 1.8892 & 1.8641 \\
\hline
\end{tabular}

TABLE 4. SLOPE EFFeCt On PASS-RAdiance, Sky-Light, Reflected Radiance On THE GRound, ABSORBED RADIANCE IN THE GROUND

\begin{tabular}{|l|l|l|l|l|l|l|}
\hline & $0-0$ & $15-0$ & $30-0$ & $15-15$ & $30-15$ & $30-30$ \\
\hline Passradiance & 19230 & 19222 & 18544 & 19230 & 18913 & 18865 \\
\hline Skylight & 8289 & 8162 & 8052 & 8280 & 8115 & 8114 \\
\hline Reflection & 15849 & 15793 & 15552 & 15685 & 15564 & 15427 \\
\hline Absorption & 56632 & 56823 & 57852 & 56805 & 57408 & 57594 \\
\hline
\end{tabular}

It is found that multiple reflections on the ground increases in accordance with decreasing the angle between two slopes (absorption in the ground). Accordingly, reflection on the ground decreases. Therefore, scattering in the atmosphere is getting small results in decreasing of the pass-radiance and skylight as shown in Table 4. From the same reason, average number of photons which hit on the ground increases in accordance with two slopes angle is decreased. TOA radiance, and average number of photons which reflected on the ground and scattered in the atmosphere then reflected on the ground again are decreased in accordance with decreasing two slopes angle as shown in Table 3.

When photons reaches at the simulation cell of $(1,1)$, then the photons reflected from the surface as shown in Figure 11.
Figure 11 shows the number of photons reflected on the ground. In the simulation, Lambertian surface (iso-tropic reflectance characteristics) is assumed for the ground surface.
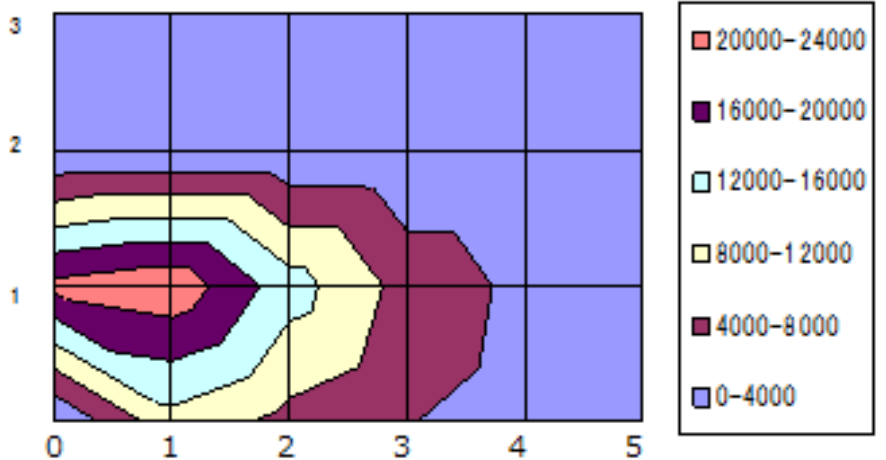

Figure 11. Number of photons reflected on the ground.

\section{Experiemntal Study}

Using Visible to Near Infrared Radiometer: VNIR imagery data of Advanced Spaceborne Thermal Emission and Reflection: ASTER (onboard Terra satellite) [9] Level 3A product (ortho-photo products) of Bands 1, 2, 3N (IFOV of $15 \mathrm{~m} \times 15 \mathrm{~m}$ ), land cover map (4 by 4 pixels) is created. Also the reflectance of the pixels in concern is estimated using the land cover map as shown in Figure 12.

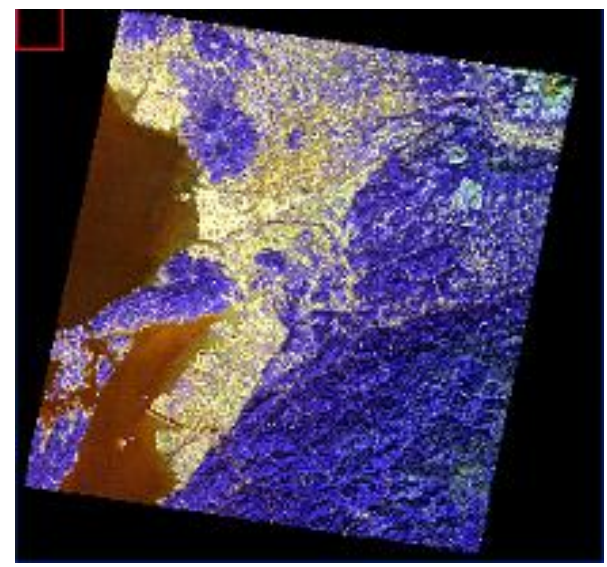

(a)Terra/ASTER VNIR image

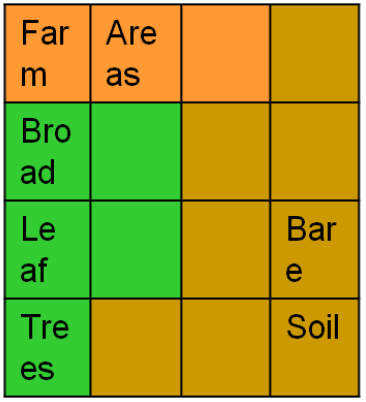

(b)Example of land cover map

Figure 12. Examples of Terra/ASTER/VNIR image and estimated land cover map. 


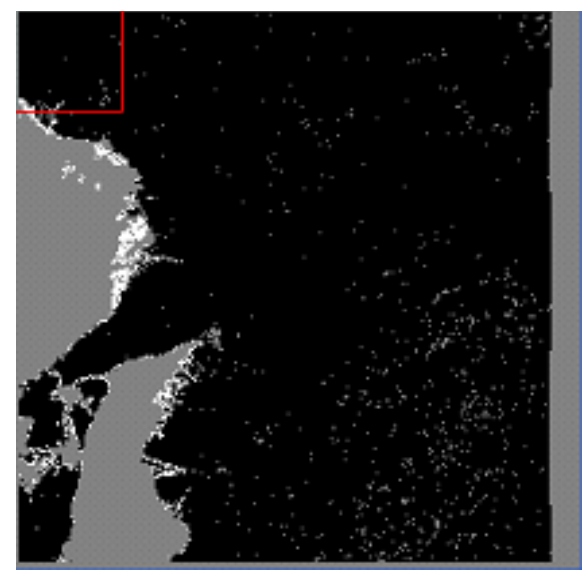

(a)Corresponding area of the area in concern which is shown in Figure 12

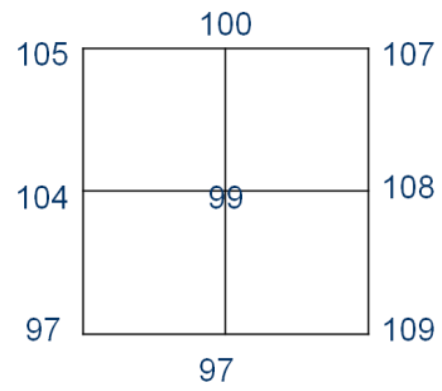

(b)Estimated digital elevation level for the four corners of 2 by 2 pixels in concern

Figure 13. Estimated elevations in concern

Utilizing ASTER data product of Level 4A of Digital Elevation Model: DEM $(30 \mathrm{~m} \times 30 \mathrm{~m})$, elevations of the pixels in concern are estimated. Thus reflectance of the ground surface can be calculated with $15 \mathrm{~m}$ of spatial resolution together with $30 \mathrm{~m}$ by $30 \mathrm{~m}$ of spatial resolution digital elevations.

Furthermore, 2 by 2 pixels of missing model can be estimated through land cover maps which are created with ASTER/VNIR imagery data based on Maximum Likelihood classification method [10],[11]. Red squares in Figure 12 and 13 are corresponding. Digital elevation at the four corners of 2 by 2 pixels can be calculated using DEM which is derived from Level 4 product of ASTER/VNIR as shown in Figure 13.

Thus the parameters for non-linear mixture model of mixed pixels are determined using MCRT. Then TOA radiance can be estimated precisely taking into account the nonlinearity of the mixels in the TOA radiance calculations with radiative transfer software codes.

\section{CONCLUSION}

Nonlinear mixing model of mixed pixels in remote sensing satellite images taking into account landscape is proposed. Most of linear mixing models of mixed pixels do not work so well because the mixed pixels consist of several ground cover targets in a nonlinear basis essentially.
In particular, mixing model should be nonlinear because reflected photons from a ground cover target are scattered with atmospheric continuants and then reflected by the other or same ground cover targets. Therefore, mixing model has to be nonlinear. Monte Carlo Ray Tracing based nonlinear mixing model is proposed and simulated. Simulation results show a validity of the proposed nonlinear mixed pixel model.

\section{ACKNOWLEDGMENT}

The author would like to thank Mrs. Yui Nishimura for her great effort to conduct simulation studies on nonlinear mixture model of mixed pixels of remote sensing satellite images

\section{References}

[1] Masao Matsumoto, Hiroki Fujiku, Kiyoshi Tsuchiya, Kohei Arai, Category decomposition in the maximum likelihood classification, Journal of Japan Society of Phtogrammetro and Remote Sensing, 30, 2, 25-34, 1991.

[2] Masao Moriyama, Yasunori Terayama, Kohei Arai, Clafficication method based on the mixing ratio by means of category decomposition, Journal of Remote Sensing Society of Japan, 13, 3, 23-32, 1993.

[3] Kohei Arai and H.Chen, Unmixing method for hyperspectral data based on subspace method with learning process, Techninical Notes of the Science and Engineering Faculty of Saga University,, 35, 1, 41-46, 2006.

[4] Kohei Arai and Y.Terayama, Label Relaxation Using a Linear Mixture Model, International Journal of Remote Sensing, 13, 16, 3217-3227, 1992.

[5] Kohei Arai, Yasunori Terayama, Yoko Ueda, Masao Moriyama, Cloud coverage ratio estimations within a pixel by means of category decomposition, Journal of Japan Society of Phtogrammetro and Remote Sensing, 31, 5, 4-10, 1992.

[6] Kohei Arai, Non-linear mixture model of mixed pixels in remote sensing satellite images based on Monte Carlo simulation, Advances in Space Research, 41, 11, 1715-1723, 2008.

[7] Kohei Arai, Kakei Chen, Category decomposition of hyper spectral data analysis based on sub-space method with learning processes, Journal of Japan Society of Phtogrammetro and Remote Sensing, 45, 5, 23-31, 2006.

[8] Kohei Arai, Adjacency effect of layered clouds estimated with MonteCarlo simulation, Advances in Space Research, Vol.29, No.19, 18071812, 2002.

[9] Ramachandran, Justice, Abrams(Edt.),Kohei Arai et al., Land Remote Sensing and Global Environmental Changes, Part-II, Sec.5: ASTER VNIR and SWIR Radiometric Calibration and Atmospheric Correction, 83-116, Springer 2010

[10] Kohei Arai, Lecture Note for Remote Sensing, Morikita Publishing Inc., (Scattering), 2004.

[11] Kohei Arai, Fundamental Theory for Remote Sensing, Gakujutsu-Tosho Publishing Co., Ltd.,(Lambertian), 2001.

\section{AUTHORS PROFILE}

Kohei Arai, He received BS, MS and PhD degrees in 1972, 1974 and 1982, respectively. He was with The Institute for Industrial Science, and Technology of the University of Tokyo from 1974 to 1978 also was with National Space Development Agency of Japan (current JAXA) from 1979 to 1990. During from 1985 to 1987 , he was with Canada Centre for Remote Sensing as a Post-Doctoral Fellow of National Science and Engineering Research Council of Canada. He was appointed professor at Department of Information Science, Saga University in 1990. He was appointed councilor for the Aeronautics and Space related to the Technology Committee of the Ministry of Science and Technology during from 1998 to 2000 . He was also appointed councilor of Saga University from 2002 and 2003 followed by an executive councilor of the Remote Sensing Society of Japan for 2003 to 2005. $\mathrm{He}$ is an adjunct professor of University of Arizona, USA since 1998. He also was appointed vice chairman of the Commission "A" of ICSU/COSPAR in 2008. He wrote 30 books and published 332 journal papers. 